\title{
Pattern of geriatric dermatoses at a Tertiary Care Teaching Hospital of South Rajasthan, India
}

\author{
Anshu Goyal', Manisha Balai ${ }^{2}$, Asit Mittal ${ }^{2}$, Ashok Kumar Khare ${ }^{2}$, Lalit Kumar Gupta ${ }^{2}$ \\ ${ }^{I}$ Consultant Dermatologist, Sikar, Rajasthan, India, ${ }^{2}$ Department of Dermatology, RNT Medical College, Udaipur, \\ Rajasthan, India
}

Corresponding author: Dr. Ashok Kumar Khare, E-mail: drakkhare@gmail.com

\begin{abstract}
Background: Geriatric health care has assumed worldwide importance due to increase in the life expectancy during the last few decades. Aging skin has a marked susceptibility to dermatologic disorders due to the structural and physiologic changes that occur as a consequence of intrinsic and extrinsic aging. Aim: This study was aimed to evaluate the magnitude, pattern, contributory factors and systemic association of various dermatoses among geriatric population. Materials and Methods: Patients aged 60 years and above attending the dermatology outpatient department during a period of one year were enrolled in the study. Detailed history taking followed by general, systemic and cutaneous examination, and relevant investigations were carried out. The findings were recorded in a proforma for analysis and interpretation of data. Results: Out of total 610 patients enrolled, $68.2 \%$ were males and $31.8 \%$ females. The male to female ratio was 2.14:1. Maximum (339;55.6\%) number of patients were in the age group of 60-69 years. Wrinkling $(273 ; 44.8 \%)$ was the commonest physiological cutaneous finding. Among the pathological changes, benign tumors $(620 ; 39.9 \%)$, nevus $(253 ; 16.3 \%)$, infection and infestation $(244 ; 15.7 \%)$, dermatitis $(158 ; 10.1 \%)$, pruritus $(78 ; 5.0 \%)$, pigmentary disorders $(67 ; 4.3 \%)$ and papulosquamous disorders $(62 ; 4.0 \%)$ were common conditions. Associated systemic illness was recorded in 180 (29.5\%) patients, of which hypertension (96; 15.7\%) was the commonest. Conclusion: With the expected increase in the geriatric population in the coming years, the dermatological problems in geriatric population assume great importance. Our study shows that physiological changes seen with ageing such as wrinkling, senile purpura, xerosis, senile comedone, atrophy and senile lentigens are major cutaneous findings. Eczemas of various types and fungal and bacterial infections are the common dermatological morbidities. These dermatological morbidities in geriatric population can be minimized by reassurance, regular use of emollients and proper education regarding routine care of skin.
\end{abstract}

Key words: Geriatric; Dermatoses; Aging

\section{INTRODUCTION}

Aging is an inevitable and continuous process with a variable spectrum of manifestations of all organ systems including the skin [1]. Due to the degenerative and metabolic changes occurring throughout the skin layers during the aging process, some inevitable changes such as dryness, wrinkling, and laxity of the skin, and atypical presentations of dermatologic diseases are observed in elderly patients $[2,3]$. These dermatoses can lead to significant morbidity and affect the quality of life but are rarely fatal [4].
The global share of older people (aged 60 years or above) increased from $9.2 \%$ in 1990 to $11.7 \%$ in 2013 , and will continue to grow as a proportion of the world population, reaching an estimated $21.1 \%$ by 2050 [5]. In India, there were 72 million elderly persons above 60 years of age as of 2001 and this number is likely to increase to 179 million in 2031 [6]. Advances in medical care has prolonged lifespan and expanded the elderly demographics, therefore now there is a greater need to evaluate various cutaneous disorders in the growing geriatric population. This study was aimed to know the magnitude, pattern, contributory factors

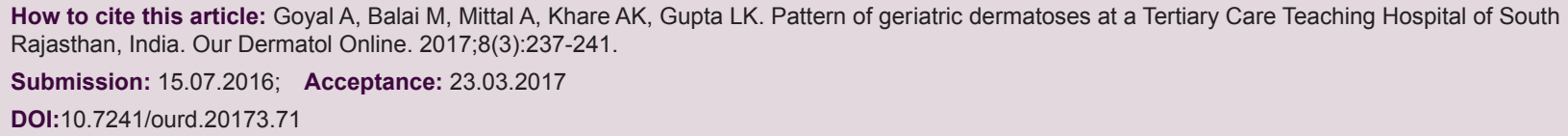


and systemic association of various dermatoses among geriatric patients in South Rajasthan.

\section{MATERIALS AND METHODS}

All the patients aged 60 years and above attending the dermatology outpatient department at a tertiary care centre during a period of one year were enrolled. A detailed history taking followed by general physical, systemic and cutaneous examination, and necessary investigations were carried out. The findings were recorded in a proforma for analysis and interpretation of data. For statistical analysis of the data, Chi-square $(\chi 2)$ test was applied. The results were considered significant at $P<0.05$.

\section{Ethics}

This study was performed on human subjects; thus, all patients were aware of the presence of the study and they were fully informed about the drug and its side-effects.

\section{RESULTS}

A total number of 610 patients were enrolled in our study, out of which $416(68.2 \%)$ were males and 194 (31.8\%) females. The male to female ratio was 2.14:1. Maximum $(339 ; 55.6 \%)$ patients were in the age group 60-69 years (Table 1). Urban patients (312; 51.1\%) slightly outnumbered rural patients (298; 48.9\%). Majority of patients $(221 ; 36.2 \%)$ had dermatoses for more than one year before they presented in OPD.

Physiological changes were found in almost all the patients; wrinkling $(273 ; 44.8 \%)$ being the commonest (Figs. 1 and 2). It was seen in $223(53.6 \%)$ males compared to 50 (25.8\%) females. Amongst the various pathological conditions observed, benign tumors were more frequent followed by nevus (Table 2). Cherry angioma was the commonest benign tumor (Table 3 ).

Amongst the infection and infestation group, fungal infection $(95 ; 15.6 \%)$ was the commonest followed by viral infection $(65 ; 10.6 \%)$, bacterial infection $(62$; $10.2 \%)$, scabies $(21 ; 3.5 \%)$ and cutaneous leishmaniasis $(1 ; 0.1 \%)$ (Table 4). Out of various other cutaneous diseases, dermatitis $(158 ; 10.1 \%)$ was also common. Among various types of dermatitis, atopic dermatitis was the commonest, followed by contact dermatitis,
Table 1: Age and gender wise distribution of geriatric patients

\begin{tabular}{lccc}
\hline Age group (years) & Male (\%) & Female (\%) & Total (\%) \\
\hline $60-69$ & $219(35.9)$ & $120(19.7)$ & $339(55.6)$ \\
$70-79$ & $153(25.1)$ & $60(9.8)$ & $213(34.9)$ \\
$80-89$ & $37(6.1)$ & $10(1.6)$ & $47(7.7)$ \\
90 and $>90$ & $7(1.1)$ & $4(0.7)$ & $11(1.8)$ \\
Total & $416(68.2)$ & $194(31.8)$ & $610(100)$ \\
\hline
\end{tabular}

Table 2: Distribution of cutaneous diseases in geriatric patients

\begin{tabular}{lcccc}
\hline Disease & $\begin{array}{c}\text { Male } \\
(\%)\end{array}$ & $\begin{array}{c}\text { Female } \\
(\%)\end{array}$ & $\begin{array}{c}\text { Total } \\
(\%)\end{array}$ & p value \\
\hline Benign tumor & $385(38.4)$ & $235(42.6)$ & $620(39.9)$ & $>0.05$ \\
Nevus & $170(16.9)$ & $83(15.1)$ & $253(16.3)$ & $>0.05$ \\
Infection \& infestation & $182(18.2)$ & $62(11.3)$ & $244(15.7)$ & $<0.05$ \\
Dermatitis & $104(10.4)$ & $54(9.8)$ & $158(10.1)$ & $>0.05$ \\
Pruritus & $48(4.8)$ & $30(5.4)$ & $78(5.0)$ & $>0.05$ \\
Pigmentary & $39(3.9)$ & $28(5.1)$ & $67(4.3)$ & $>0.05$ \\
Papulosquamous & $37(3.7)$ & $25(4.5)$ & $62(4.0)$ & $>0.05$ \\
Autoimmune \& metabolic & $6(0.6)$ & $9(1.6)$ & $15(1.0)$ & $<0.05$ \\
Callosity/keratoderma & $9(0.9)$ & $6(1.1)$ & $15(1.0)$ & $>0.05$ \\
Premalignant \& malignant & $5(0.5)$ & $2(0.4)$ & $7(0.5)$ & $>0.05$ \\
Vesicobullous & $2(0.2)$ & $5(0.9)$ & $7(0.5)$ & $<0.05$ \\
Miscellaneous & $15(1.5)$ & $12(2.2)$ & $27(1.7)$ & $>0.05$ \\
Total & $1002(100)$ & $551(100)$ & $1553^{*}(100)$ & \\
\hline
\end{tabular}

${ }^{*}$ Some patients had more than one entity

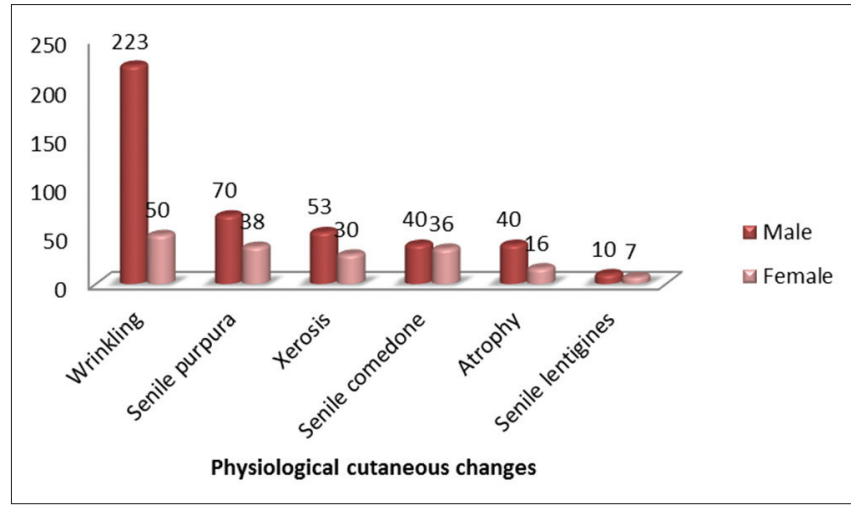

Figure 1: Physiological cutaneous change in geriatric patients.

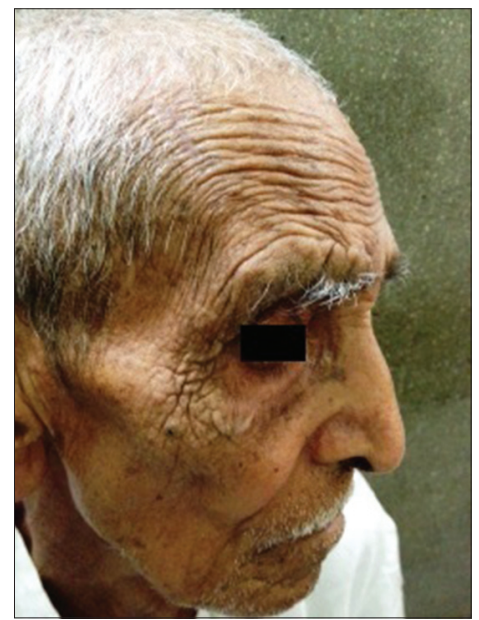

Figure 2: Wrinkling over forehead and senile comedones on right cheek. 
photodermatitis, lichen simplex chronicus and nummular dermatitis. Frequency of pruritus was $78(5 \%)$.

Pigmentary disorders were observed in 67 (4.3\%); idiopathic guttate hyomelanosis being the commonest followed by vitiligo. The relative incidence of papulosquamous disorders was 62 (4.0\%); psoriasis being the commonest and premalignant and malignant neoplasms were $7(0.5 \%)$.

Associated systemic diseases were recorded in $180(29.5 \%)$ patients, of which hypertension (96; 15.7\%) was the commonest (Fig. 3).

\section{DISCUSSION}

Skin changes in the elderly occur either due to natural aging process, or due to pathological dermatological conditions. Compared to general population, the pattern of cutaneous changes seen in elderly population may be different or unique. In addition, elderly patients often have multiple medical problems and because of this they often need multiple medications, and all this adds to dermatological morbidity. Therefore the ambit of dermatological care needed for the elderly population is different from that for other age groups.

A total of 610 patients aged 60 years and above were examined over a period of one year. The hospital incidence of geriatric patients was $1.54 \%$ in this study. Males outnumbered females with male to female ratio 2.14:1. This is largely in tune with other studies [7-13]. In a few studies female have outnumbered male patients $[14,15]$.

Most common (55.6\%) age group recorded in our study was 60-69 years, which is similar to other studies $[13,16]$. Because different studies have chosen different age parameters for elderly population, it is difficult to draw a comparison. Majority of our patients had the disease for more than one year before they sought medical consultation. This delay can be attributed to two reasons- 1) Most dermatoses in elderly people either do not cause significant morbidity and mortality or 2) Because of dependency on others elderly people do not find it easy to visit hospital. There is a very thin line in deciding what is physiological and what is pathological in older person's skin. Many changes and lesions are normal, except occasionally in degree and number. In this study we considered wrinkling, senile
Table 3: Pattern of benign tumors in geriatric patients

\begin{tabular}{lccc}
\hline Disease & Male (\%) & Female (\%) & Total (\%) \\
\hline Cherry angioma & $156(40.5)$ & $90(38.3)$ & $246(39.7)$ \\
Dermatosis papuosa nigra & $125(32.5)$ & $55(23.4)$ & $180(29.0)$ \\
Skin tag & $60(15.6)$ & $67(28.5)$ & $127(20.5)$ \\
Seborrhoeic keratosis & $31(8.0)$ & $13(5.5)$ & $44(7.1)$ \\
Milia & $11(2.9)$ & $10(4.3)$ & $21(3.4)$ \\
Epidermoid cyst & $2(0.5)$ & 0 & $2(0.3)$ \\
Total & $385(100)$ & $235(100)$ & $620(100)$ \\
\hline
\end{tabular}

Table 4: Pattern of infections and infestations in geriatric patients

\begin{tabular}{lcccc}
\hline Diseases & $\begin{array}{c}\text { Male } \\
(\%)\end{array}$ & $\begin{array}{c}\text { Female } \\
(\%)\end{array}$ & $\begin{array}{c}\text { Total } \\
(\%)\end{array}$ & p value \\
\hline Fungal infections & $70(11.5)$ & $25(4.1)$ & $95(15.6)$ & $>0.05$ \\
Dermatophytic & $58(9.5)$ & $15(2.5)$ & $73(12.0)$ & \\
Candidiasis & $7(1.1)$ & $6(1.0)$ & $13(2.1)$ & \\
Intertrigo & $3(0.5)$ & $2(0.3)$ & $5(0.8)$ & \\
Pityriasis versicolor & $2(0.3)$ & $2(0.3)$ & $4(0.6)$ & \\
Viral infections & $46(7.5)$ & $19(3.1)$ & $65(10.6)$ & $>0.05$ \\
Herpes zoster & $40(6.6)$ & $16(2.6)$ & $56(9.2)$ & \\
Herpes simplex & $3(0.5)$ & $2(0.3)$ & $5(0.8)$ & \\
Herpes genitalis & $2(0.3)$ & 0 & $2(0.3)$ & \\
Warts & $1(0.1)$ & $1(0.1)$ & $2(0.3)$ & \\
Bacterial infections & $48(7.9)$ & $14(2.3)$ & $62(10.2)$ & $>0.05$ \\
Folliculitis & $16(2.6)$ & $4(0.6)$ & $20(3.2)$ & \\
Leprosy & $11(1.8)$ & $3(0.5)$ & $14(2.3)$ & \\
Furuncle & $7(1.2)$ & $4(0.6)$ & $11(1.8)$ & \\
Carbuncle & $4(0.6)$ & 0 & $4(0.6)$ & \\
Cellulitis & $3(0.5)$ & $1(0.1)$ & $4(0.6)$ & \\
Others & $7(1.2)$ & $2(0.3)$ & $9(1.5)$ & \\
Infestations & $18(2.9)$ & $4(0.7)$ & $22(3.6)$ & $>0.05$ \\
Scabies & $17(2.8)$ & $4(0.7)$ & $21(3.5)$ & \\
Leishmaniasis & $1(0.1)$ & 0 & $1(0.1)$ & \\
Total & 182 & 62 & 244 & \\
\hline
\end{tabular}

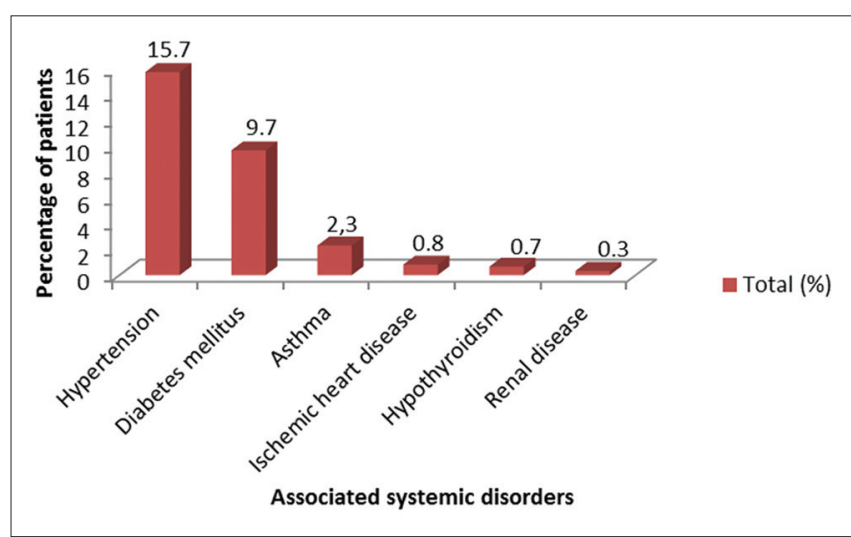

Figure 3: Associated systemic conditions in geriatric patients.

purpura, xerosis, senile comedone, atrophy and senile lentigens as physiological.

Wrinkling was the commonest physiological change seen in the present study $273(44.8 \%)$. Similar findings have been reported in other studies also $[9,10,17]$. Presence of wrinkling in more number of males $223(53.6 \%)$ compared to females $50(25.8 \%)$ could be due to more outdoor activity in males exposing them 
to increased ultra violet rays. Senile purpura was seen in $108(17.7 \%)$ patients in our study. We found xerosis in $83(13.6 \%)$ patients. Various studies have reported prevalence of xerosis from $7 \%$ to $99.8 \%[7,12-14,18]$. Senile comedones were seen in $76(12.5 \%)$ patients in our study. Almost similar incidence $(11.5 \%)$ was observed in another study [7] while study by Raveendra L [12] reported slightly higher (28\%) incidence. Senile lentigines were observed in $2.8 \%$ of patients. Grover et al [9], Raveendra L [12] and Sheethal et al [13] reported it in $10 \%, 15 \%$ and $30 \%$ patients respectively.

Of the pathological cutaneous findings, benign tumors were the commonest $(620 ; 39.9 \%)$. The frequency of benign tumor varies between $1.7 \%$ to $74.5 \%$ in different studies $[7,9,10-12,14-16,19,20]$. Cherry angioma $(39.7 \%)$ was the commonest benign tumor observed in our study. This correlates with other studies $[7,12]$.

The relative incidence of infections and infestations was 244 (15.7\%). The incidence of this compares well with other studies $[11,13,15,16]$. Some studies though have reported a higher incidence $[7,9,12]$. Fungal infections were the commonest infections seen in elderly. This is in unison with other studies $[4,7,9,10-12,14,16,19,21]$. The higher incidence of fungal infections in elderly people is probably the result of lack of personal care, decrease in epidermal turnover and immunologic functions [3]. Viral $(10.6 \%)$ and bacterial $(10.2 \%)$ infections were the next common infections; which is much lower than fungal infections. This is consistent with the findings of other studies $[7,9,10,12,15,19]$. Factors like poor hygiene, neglect, underlying disease like diabetes, bedridden status may also contribute to infections.

Dermatitis (10.1\%) and pruritus (5.0\%) were other common conditions. The figure of dermatitis is consistent with the finding of Patange et al [7]. A higher incidence has been reported in some other studies $[4,9-13,15,19,21]$. Atopic dermatitis was the commonest $(5.2 \%)$ dermatitis seen in our study. Similar findings were reported by Chopra [8]. The observed prevalence of pruritus in various studies ranges from $7.3 \%$ to $78.5 \%[4,7,11-16,18-21]$.

In different studies, the incidence of premalignant and malignant neoplasm has varied from $0.5 \%$ to $15.5 \%$. In our study, frequency of these skin tumors $(0.5 \%)$ was lower than the other studies $[11,14,16,19]$. Indian study by Sayal et al [17] has also reported lower incidence $(0.3 \%)$ of skin tumors. Raveendra L [12] found no malignant skin conditions in their study. This lower incidence of skin tumors in Indian studies compared to studies from west can be attributed to the fact that pigmented skin offers more protection against ultraviolet radiation compared to individual with Fitzpatrick skin types I and II.

Systemic diseases were recorded in 180 (29.5\%) patients. A similar incidence of systemic disease has been reported in another study also [7]. We found hypertension $(96 ; 15.7 \%)$ as the commonest problem. This is shared by other studies $[9,12,16]$ also, however incidence was much higher. Diabetes mellitus (59; 9.7\%) was the second most common systemic disease in our study. This is similar to other studies $[9,12,16]$ while some other studies found it to be the commonest systemic disease $[7,14,18]$.

\section{CONCLUSION}

With the expected increase in the geriatric population in the coming years, the dermatological problems in geriatric population are of great relevance. Our study shows that physiological changes seen with ageing such as wrinkling, senile purpura, xerosis, senile comedone, atrophy and senile lentigens are major cutaneous findings. Eczemas of various types and fungal and bacterial infections are the common dermatological morbidities. Benign tumors such as cherry angiomas are also commonly seen but incidence of skin malignancy is low in our geriatric population. The dermatological morbidities in geriatric population can be minimized by reassurance, regular use of emollients and proper education regarding routine care of skin.

\section{Statement of Human and Animal Rights}

All procedures followed were in accordance with the ethical standards of the responsible committee on human experimentation (institutional and national) and with the Helsinki Declaration of 1975, as revised in 2008 .

\section{Statement of Informed Consent}

Informed consent was obtained from all patients for being included in the study.

\section{REFERENCES}

1. Winker MA. Aging in the 21st century: a call for papers. J Am Med Assoc. 2002;287:1326. 


\section{www.odermatol.com}

2. Jafferany M, Huynh TV, Silverman MA, Zaidi Z. Geriatric dermatoses: a clinical review of skin diseases in an ageing population. IntJ D. 2012;51:509-22.

3. Havlik NL, Fitzpatrick TB, Kligman AM, et al. Geriatric dermatology. In: Freedberg IM, Eisen AZ, Wolff K, et al., eds. Fitzpatrick's Dermatology in General Medicine, $5^{\text {th }}$ edn. New York: McGraw-Hill, 1999: 1707-24.

4. Thapa DP, Jha AK, Kharel C, Shrestha S. Dermatological problems in geriatric patients: a hospital based study. Nepal Med Coll J. 2012;14:193-5.

5. World Health Organization. Good Health Adds Life to YearsGlobal Brief for World Health Day 2012. Geneva: World Health Organization, 2012. Available from: http://whqlibdoc.who.int/ hq/2012/WHO_DCO_WHD_2012.2_eng.pdf.

6. Rajan SI, Sarma PS, Mishra US. Demography of Indian aging, 2001-2051. J Aging Soc Policy. 2003;15:11-30.

7. Patange VS, Fernandez RJ. A study of geriatric dermatoses. Indian J Dermatol Venereol Leprol. 1995;61:206-8.

8. Chopra A. Skin diseases in the elderly. Indian J Dermatol Venereol Leprol. 1999;65:245-6.

9. Grover S, Narasimhalu C. A clinical study of skin changes in geriatric population. Indian J Dermatol Venereol Leprol. 2009;75:305-6.

10. Pavithra S, Shukla P, Pai GS. Cutaneous manifestations in senile skin in coastal Goa. NJDVL. 2010;9:1-6.

11. Bilgili SG, Karadag AS, Ozkol HU, Calka O, Akdeniz N. The prevalence of skin diseases among the geriatric patients in Eastern Turkey. J Pak Med Assoc. 2012;62:535-9.

12. Raveendra L. A clinical study of geriatric dermatoses. Our Dermatol Online. 2014;5:235-9.

13. Sheethal MP, Shashikumar BM. A cross-sectional study on the dermatological conditions among the elderly population in Mandya city. Int J Med Sci Public Health. 2015;4:467-70.

14. Durai PC, Thappa DM, Kumari R, Malathi M. Aging in elderly: Chronological versus photoaging. Indian J Dermatol. 2012;57:343-52.

15. Kartal D, Cinar SL, Akin S, Ferahbas A, Borlu M. Skin findings of geriatric patients in Turkey: A 5-year survey. Dermatol Sinica. 2015;33: 196-200.

16. Darjani A, Mohtasham-Amiri Z, Amini KM, Golchai J, SadreEshkevari S, Alizade N. Skin disorders among elder patients in a referral center in Northan Iran (2011). Dermatol Res Pract. 2013;2013:193205.

17. Sayal SK, Rajbhandari S, Malik AK, Gupta CM. A study of dermatological disorders in geriatric age group. Indian J Dermatol Venereol Leprol. 1998;64:270-2.

18. Sahoo A, Singh PC, Pattnaik S, Panigrahi RK. Geriatric Dermatoses in Southern Orissa. Indian J Dermatol. 2000;45:66-8.

19. Yalcin B, Tamer E, Toy GG, Oztas P, Haryan M, Alli N. The prevalence of skin diseases in the elderly: analysis of 4099 in geriatric patients. Int J Dermatol. 2006;45:672-6.

20. Liao YH, Chen KH, Tseng MP, Sun CC. Pattern of skin disease in a geriatric patient group in Taiwan: a 7-year survey from the outpatient clinic of a university medical center. Dermatology. 2001;203:308-13

21. Sirisha NL, Kumar MP, Sowjanya S. Dermatological problems in geriatric patients: a hospital based study. Indian J Applied Research. 2015;5:534-5.

Copyright by Anshu Goyal, et al. This is an open access article distributed under the terms of the Creative Commons Attribution License, which permits unrestricted use, distribution, and reproduction in any medium, provided the original author and source are credited

Source of Support: Nil, Conflict of Interest: None declared. 